論文

초기자세 획득을 위한 패턴 매칭을 이용한 광학 방식 헤드 트랙커

김영일*, 박찬국**

\title{
Optical Head Tracker using Pattern Matching for Initial Attitude
}

\author{
Youngil Kim* and ChanGook Park**
}

\begin{abstract}
This paper is the study which is head tracker using pattern matching. Proposal algorithm obtains initial attitude of head tracker using pattern matching. Optical head tracker consists of infrared LEDs(features) which are attached helmet as pattern, stereo infrared cameras. Proposal algorithm analyzes patterns by error rate of feature distance and estimates feature characteristic number. Initial attitude of head tracker is obtained to compare map data and feature characteristic number.

\section{초록}

본 논문은 헤드 트랙커(Head Tracker) 시스템에 패턴 매칭을 적용한 연구이다. 제안하 는 알고리즘은 패턴을 통하여 헤드 트랙커의 초기자세를 빠르고 쉽게 획득하는 것이다. 광학 방식 헤드 트랙커는 적외선 $\operatorname{LED}($ 특징점)를 헬멧에 부착하고, 스테레오 카메라로 영 상을 획득한다. 영상 분석시 발생하는 특징점간 거리 오차율을 바탕으로 패턴을 이루며 특징점을 부착한다. 특징점간 거리를 이용해 패턴 분석을 하고, 획득된 패턴을 바탕으로 특징점에 고유 번호를 부여한다. 맵 데이터와 특징점 고유 번호를 비교함으로써 헤드 트 랙커의 초기자세를 추정한다.
\end{abstract}

Key Words : Head Tracker(헤드 트랙커), Pattern Matching(패턴 매칭), Infrared LED (적외선 $\mathrm{LED}$ )

\section{I. 서 론}

항공기의 중요성이 증가함에 따라 조종사가 다루어야 할 장비도 증가하고 있다. 20세기 초 항공기가 개발된 이후로 기술이 발전함에 따라 항공기의 장비 또한 급속도로 첨단화 되고 있다. 아날로그 및 수동으로 작동되던 장비들이 디지털 및 자동으로 바뀌었고, 레이더, $\mathrm{HUD}(\mathrm{Head} \mathrm{Up}$ Display), $\mathrm{HMD}(\mathrm{Head}$ Mounted Display)와 같은 새로운 장비도 도입되고 있다. 이런 기술을 바탕

† 2009년 1월 15일 접수 2009년 4월 15일 심사완료

* 정회원, 서울대학교 기계항공공학부 대학원/항공우주신기술연구소

** 정회원, 서울대학교 기계항공공학부/항공우주신기술연구소 교신저자, E-mail : chanpark@snu.ac.kr

서울시 관악구 관악로 599번지
으로 군수 및 민수 분야에서 항공기의 역할이 증 가하고 있다. 예를 들어 현대 전쟁에서 공군 전 력이 차지하는 비중은 점점 증가하고 있으며, 제 공권의 획득이 전쟁의 승리와 직결되고 있다[1].

항공기 장비와 임무의 증가는 조종사의 원활 한 임무 수행에 부정적인 영향을 주며, 이런 문 제점을 해결하기 위해 다양한 방법들이 연구되고 있다. 조종사 머리의 위치 및 자세를 측정하는 헤드트랙커도 이와 같은 장비들 중 하나이다[2].

헤드 트랙커에 주로 사용되는 센서는 자기장 방식과 광학 방식이 있다. 자기장 방식의 경우 높은 정확도를 가지고 있기 때문에 많이 사용되 고 있으나 신호가 연기되어 들어오기 때문에 항 공기에 적용이 힘들다. 광학 방식의 경우 높은 정밀도를 가진다는 장점이 있지만, 영상 처리에 
따른 계산량 증가로 시스템을 운용하는데 어려움 이 있다[3]. 그러나 최근 영상 관련 기술의 발달 로 광학 방식에 대한 연구가 활발히 진행되고 있 다.

광학 방식 헤드 트랙커는 아웃사이드-인 방식 (outside-in method)과 인사이드-아웃 방식(inside -out method)으로 구분된다. 아웃사이드-인 방식 은 외부에 존재하는 카메라가 사용자의 머리에 장착된 광학 목표물(optical target)를 추적하는 방식이다. 인사이드-아웃 방식은 카메라가 사용 자의 머리에 장착되어 외부의 광학 목표물을 추 적하는 방식이다[4]. 일반적으로 항공기에서 사용 되는 헤드 트랙커는 전체 면적이 좁은 조종석 (cockpit)에서 사용되기 때문에 적은 개수의 광학 목표물로 머리의 자세 추정이 가능한 아웃사이드 -인 방식을 적용한다.

아웃사이드-인 방식의 광학 방식 헤드 트랙커 는 헬멧에 부착된 광학 목표물을 획득하여 헬멧 의 움직임을 추정한다. 현재 광학 목표물을 획득 하는 부분은 영상 분야를 통해 많은 연구가 진행 되고 있다[4,5].

국외에서는 광학 목표물을 인식하기 위하여 특정한 모양의 패턴을 부착하거나 RGB 레벨의 발광 센서를 사용한다[6,7]. 국내에서는 적외선 LED 센서를 무작위로 배치하고 초기자세를 얻기 위해 LED 센서를 하나씩 점등하는 방식을 제안 하였으나, 헬멧의 초기 위치 및 자세를 알기 위 해 많은 시간과 노력이 필요하다[8]. 그러므로 헤 드 트랙커의 활용을 위해서 초기자세를 획득하는 과정을 개선하는 연구가 필요하다.

본 논문에서는 초기자세 획득 방법에 관하여 기 존 헤드 트랙커의 단점을 개선하기 위하여 패턴을 이용한 방식을 제안한다. 그리고 패턴의 결정 방식 과 분석 방식에 대한 연구를 통하여 특징점간 거리 를 이용해 패턴을 획득한다. 획득된 패턴을 통해 LED 센서에 대한 특징점 고유 번호를 부여함으 로써 특징점의 기준 좌표인 맵 데이터와 비교하 여 머리의 위치 및 자세를 획득한다. 이를 바탕 으로 회전 실험을 통하여 제안하는 알고리즘의 성능을 분석한다.

\section{II. 본 론}

\section{1 광학 방식 헤드 트랙커 구성}

1) 시스템 구성

헬멧에 적외선 LED 센서를 부착하여 특징점 을 만들고 적외선 스테레오 카메라를 통해 특징

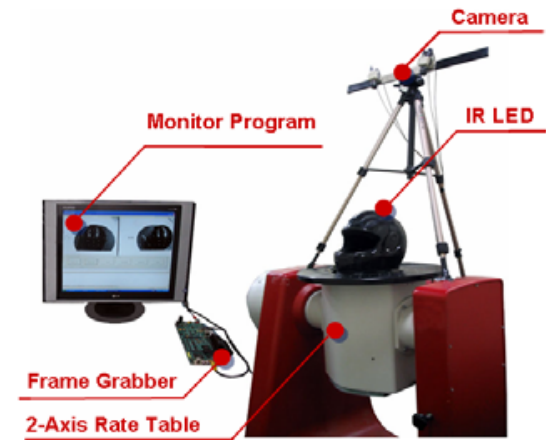

그림 1. 광학 방식 헤드 트랙커

점의 움직임을 추정하면서 머리의 위치 및 자세 를 획득한다. 영상편집보드로 Matrox사의 Meteor2-MC/4 frame grabber를 사용한다. 그림 1은 개발중인 광학 방식 헤드 트랙커 시스템을 나타낸 것이다.

2) 기존 방식의 문제점

기존의 광학 방식 헤드 트랙커 시스템은 적외 선 LED 센서(특징점)를 무작위로 배치하였다[6]. 이와 같은 배치는 헤드 트랙커 제작시 편리하다 는 장점이 있다. 그러나 기존 광학 방식 헤드 트 랙커 시스템은 헬멧이 정지된 상태에서 특징점을 하나씩, 일정 시간 동안 점등을 통하여 초기 위 치 및 자세를 획득한다. 즉, 초기자세 획득을 위 해 많은 시간이 소모된다는 것을 의미한다. 그림 2는 기존 헤드 트랙커 시스템의 헬멧을 나타낸 것이며 표시된 작은 원은 무작위로 배치된 특징 점을 의미한다.

\section{2 패턴 매칭을 위한 패턴 제작 방식}

헤드 트랙커의 초기자세를 빠르고 쉽게 획득 하기 위해 헬멧의 특징점은 일정한 패턴을 형성 하며 배치하는 방식을 제안한다. 영상 처리 알고 리즘을 통하여 패턴의 위치를 파악할 수 있다면 초기자세를 빠르게 획득할 수 있을 것이다.

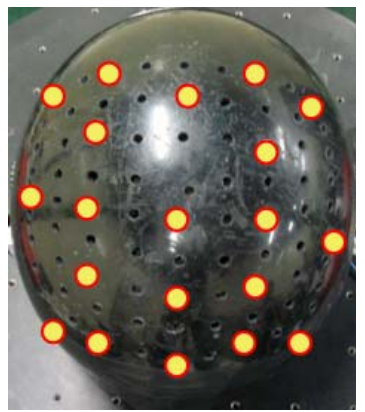

그림 2. 기존 시스템에 사용된 헬멧 


\section{1) 패턴 모양}

특징점간 정해진 거리를 통하여 패턴을 분석 하는 방식을 제안한다. 따라서 패턴을 이루는 특 징점간의 길이의 개수가 적을수록 패턴을 분석하 는 것이 빠르고 편리해진다.

특징점의 수와 그에 따른 특징점간의 길이의 개수는 식(1)과 같다.

$$
x=n+\frac{n(n-3)}{2} \quad(n \geq 3)
$$

여기서 $n$ 은 특징점의 개수이며 $x$ 는 특징점간의 길이의 개수이다. 따라서 최소한 안전한 패턴이 1 개 이상 보이도록 최소 형태로 해주는 경우는 특징점간의 길이의 개수가 가장 적은 패턴의 모 양은 삼각형이다.

2) 특징점간 거리 실험

특징점간 거리를 이용하여 패턴을 구분하기 위해서는 특징점간의 거리에 따른 오차를 분석해 야 한다. 그 이유는 다음과 같다. 첫째, 특징점간 간격이 좁다면 특징점을 서로 다른 점이라 구분 할 수 없다. 영상을 통해 특징점을 획득하는 방 식은 LED에서 방사되는 빛의 그레이 레벨(grey level)을 이용한다[6]. 만약 특징점간 간격이 좁아 특징점이 방사하는 빛이 겹치면 서로 다른 특징 점으로 구분할 수 없다. 즉, 그림 3 의 좌측 첫 번 째 줄 2개의 특징점은 너무 가까이 붙어 있어 우 측의 그림처럼 방사되는 빛(점선 원)이 겹치는 것을 알 수 있다. 그러나 두 번째 줄과 세 번째 줄은 특징점간 거리가 충분히 떨어져 있어 방사 되는 빛이 겹치지 않는다.

둘째, 영상을 통해 획득되는 특징점간 거리는 실제 길이와 정확히 일치하지 않는다. 특징점간 거리는 각 특징점의 중심간 거리로 계산하는데, 중심은 특징점의 방사 형태에 따라 달라지기 때 문에[6] 특징점의 위치와 카메라와의 각도에 따 라 달라진다. 예를 들어 그림 4 는 헬멧에 2 개의 삼각형 패턴(6개의 특징점)을 부착한 것이다. 각 패턴의 선분에 쓰여 있는 숫자는 특징점간 실제 길거리이다.

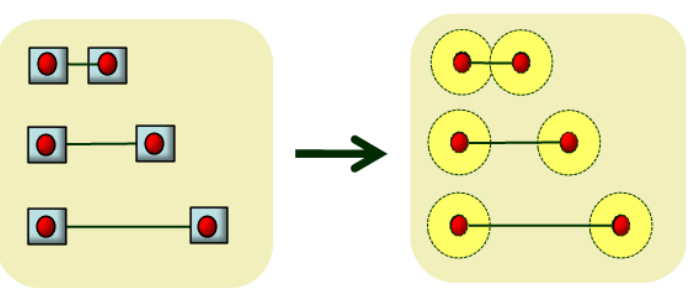

그림 3. 특징점간 거리 실험

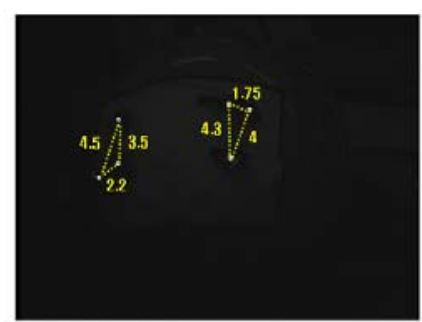

그림 4. 헬멧에 부착된 패턴과 실제 길이

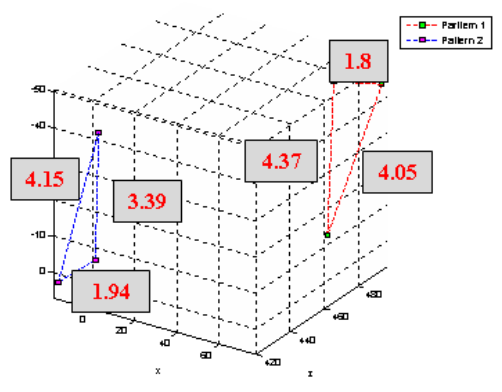

그림 5. 계산된 특징점간 길이

그림 5는 영상 처리 알고리즘을 통하여 획득 된 특징점간 거리이다. 왼쪽 패턴의 경우 각 선 분의 오차율이 최대 $11.8 \%$ 까지 계산되나 오른쪽 패턴의 경우 최대 $2.9 \%$ 에 불과하다.

그러므로 오차율을 고려하지 않고 특징점간 거리를 비슷하게 하여 제작한다면 영상 처리시 다른 패턴으로 잘못 판단되는 경우가 발생할 수 있다.

\section{3) 패턴 길이 형성}

특징점간 거리 실험을 통하여 2개의 특징점을 구분 지을 수 있는 최소의 길이와 시스템 환경에 서 나타나는 최대 오차율을 파악할 수 있을 것이 다. 특징점을 구분 지을 수 있는 최소의 길이를 $a_{1}$ 이라 하고 오차율을 $\alpha$ 라 한다면 식(2)를 만족 한다.

$$
a_{1}=y_{1} \times((100-\alpha) / 100)
$$

여기서 $y_{1}$ 은 패턴을 이루는 특징점간 거리 중 가장 작은 길이이다. 패턴을 이루게 되는 두 번 째 작은 길이는 식(3)과 식(4)의 관계에 의해 얻 어진다.

$$
\begin{gathered}
a_{2}=y_{1} \times((100+\alpha) / 100) \\
y_{2}=a_{2} /((100-\alpha) / 100)
\end{gathered}
$$


여기서 $y_{2}$ 는 패턴을 이루는 특징점간 거리 중 두 번째로 작은 길이이고, $a_{2}$ 는 $y_{1}$ 과 $y_{2}$ 를 구분 해주는 경계값이다. 즉, 영상 처리 알고리즘을 통 하여 획득한 값이 $a_{1}$ 과 $a_{2}$ 사이이면 실제 길이는 $y_{1}$ 으로 인식하고, $a_{2}$ 와 $a_{3}$ 사이이면 실제 길이는 $y_{2}$ 로 인식한다.

그리고 패턴간 거리는 충분히 떨어뜨려 배치 함으로써 다른 패턴의 특징점들이 모여 새로운 패턴을 형성하지 않게 한다. 단, 패턴의 배치는 머리의 어떤 움직임에서도 최소한 하나의 패턴이 보이도록 한다.

\section{3 패턴 매칭 알고리즘}

영상 처리에 의해 획득된 특징점으로 패턴을 획 득하는 과정이 필요하다. 그 과정은 다음과 같다.

1) 패턴 획득

특징점의 중심을 획득한 후 특징점간 거리를 계산하여 실제 헬멧에 부착한 특징점간 거리 데 이터와 비교하여 패턴을 획득한다. 이 때, 모든 특징점간 거리를 계산하고 패턴을 구분한다면 계 산량이 많아진다. 계산량을 줄이기 위해 패턴을 구성하는 가장 긴 선분의 최대 오차값 이상은 무 시한다. 즉, 가장 긴 선분의 길이를 $y_{n}$ 이라 한다 면 패턴을 형성하는 특징점간 거리는 $a_{n+1}$ 이하로 만 계산될 것이다. 이것은 $a_{n+1}$ 이상의 값은 다른 패턴을 이루는 특징점간 거리라는 것을 뜻하기 때문에 계산에서 제외한다.

2) 특징점 고유 번호 획득

머리의 위치 및 자세를 획득하기 위해서는 기 준이 되는 특징점(맵 데이터)의 위치에 대한 특 징점의 현재 위치를 알고 있어야 한다. 맵 데이 터는 회전 실험을 통하여 획득한다[10]. 이것을 바탕으로 현재 획득된 특징점의 비교를 빠르게 하기 위하여 특징점 고유 번호를 부여한다. 특징 점 고유 번호(feature characteristic numbers)는 패턴을 분석하는 과정에서 획득한다.

3) 자세 획득

맵 데이터와 현재 보이는 특징점간 관계는 최 소자승법(linear square method)을 통해 헤드 좌 표계(head frame)를 기준으로 회전 행렬을 획득 함으로써 계산할 수 있다. 식(5)는 맵 데이터와 획득한 특징점과의 좌표관계를 나타낸 것이다.

$$
\begin{array}{ccc}
P_{1}^{C}=R^{*} P_{1}^{M}+T \\
\vdots & \vdots & \vdots \\
P_{i}^{C}= & R^{*} P_{i}^{M}+T
\end{array}
$$

여기서 $p_{i}^{C}$ 는 $i$ 번째 특징점의 현재 3 차원 위치 이고, $p_{i}^{M}$ 는 $i$ 번째 특징점의 맵 데이터의 위치 이고, $R$ 은 회전 행렬을 의미한다. 식(5)는 식(6) 과 같이 변형이 가능하다.

$$
\left[\begin{array}{c}
\left(p_{1}^{C}-p_{2}^{C}\right)^{T} \\
\vdots \\
\left(p_{i-1}^{C}-p_{i}^{C}\right)^{T}
\end{array}\right]^{T}=R\left[\begin{array}{c}
\left(p_{1}^{M}-p_{2}^{M}\right)^{T} \\
\vdots \\
\left(p_{i-1}^{M}-p_{i}^{M}\right)^{T}
\end{array}\right]^{T}
$$

$R$ 은 최소자승제곱법을 사용하여 식(7)과 같이 획득할 수 있다.

$$
R=\left[\begin{array}{c}
\left(p_{1}^{C}-p_{2}^{C}\right)^{T} \\
\vdots \\
\left(p_{i-1}^{C}-p_{i}^{C}\right)^{T}
\end{array}\right]^{T}\left[\begin{array}{c}
\left(p_{1}^{M}-p_{2}^{M}\right)^{T} \\
\vdots \\
\left(p_{i-1}^{M}-p_{i}^{M}\right)^{T}
\end{array}\right]\left(\left[\begin{array}{c}
\left(p_{1}^{M}-p_{2}^{M}\right)^{T} \\
\vdots \\
\left(p_{i-1}^{M}-p_{i}^{M}\right)^{T}
\end{array}\right]\left[\begin{array}{c}
\left(p_{1}^{M}-p_{2}^{M}\right)^{T} \\
\vdots \\
\left(p_{i-1}^{M}-p_{i}^{M}\right)^{T}
\end{array}\right]\right)^{T}
$$

$R$ 을 식(8)과 같이 표현할 수 있다고 할 때,

$$
R=\left[\begin{array}{lll}
r_{11} & r_{12} & r_{13} \\
r_{21} & r_{22} & r_{23} \\
r_{31} & r_{32} & r_{33}
\end{array}\right]
$$

머리의 자세 롤 $(\phi)$, 피치 $(\theta)$, 요 $(\varphi)$ 는 식(9)와 같이 표현할 수 있다.

$\phi=\arctan \left\{\frac{r_{32}}{r_{33}}\right\}, \theta=\arcsin \left\{-r_{31}\right\}, \varphi=\arctan \left\{\frac{r_{21}}{r_{11}}\right\}$

4) 가상의 점 생성

머리의 위치 및 자세를 추정하기 위해서는 최 소자승법이 사용되는데 이 때, 최소 4 개의 특징 점이 필요하다. 그러나 패턴 매칭 알고리즘에서 는 패턴 단위로 특징점을 획득할 수 있기 때문에 1 개의 패턴만 보인다면 1 개의 특징점이 부족하 다. 그래서 패턴을 통해 획득되는 3개의 특징점 을 통해 패턴의 무게중심에 가상의 특징점을 생 성한다. 가상의 특징점을 이용하면 1 개의 패턴만 획득될 때도 머리의 위치 및 자세를 추정할 수 있다. 그림 6 은 패턴을 이루는 3 개의 특징점과 가상의 특징점(가운데)을 나타내고 있다.

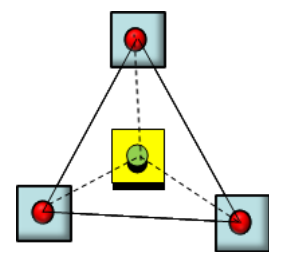

그림 6. 가상의 특징점 생성 


\section{4 실험 결과}

패턴 매칭 알고리즘을 기반으로 실험을 하고 그 결과를 살펴본다. 특징점간 거리 실험, 특징점 고유 번호 획득 결과 그리고 헬멧의 회전 실험에 대한 결과를 살펴본다.

1) 특징점간 거리 실험

특징점간 최소 구분 거리와 패턴 매칭 알고리 즘을 위한 거리 계산 오차율을 파악하기 위해 카 메라에 대한 특징점의 자세와 특징점간 거리를 변화시키며 반복적으로 오차율을 계산하였다. 실 험 환경은 항공기 조종석과 같은 환경이며, 머리 의 회전 각도를 고려하여 다양한 각도에서 실험 하였다. 표 1 은 실험 결과의 일부이다.

표 1 에서 나타나듯이 $1.25 \mathrm{~cm}$ 의 경우 항상 서 로 다른 특징점으로 인식하지 못하기 때문에 최 소 구분 거리는 $1.5 \mathrm{~cm}$ 이다. 또한 최대 오차율은 $12 \%$ 가 이내라는 것을 알 수 있다. 그림 7 은 특 징점 거리 실험을 기초로 하여 결정된 패턴을 실 제로 헬멧에 배치된 특징점의 모습이다.

2) 특징점 고유 번호 획득

그림 7과 같이 배치된 특징점을 패턴 매칭 알 고리즘을 통해 특징점 고유 번호를 획득하였다.

그림 8 은 일차적인 매칭의 결과이며 $\mathrm{y}$ 축 값이 작은 순서대로 임시로 특징점의 번호가 부여된 것을 나타내고 있다.

그림 9는 패턴 매칭 알고리즘을 적용한 결과 이다.

\section{표 1. 특징점 간 거리에 따른 계산 오차율}

\begin{tabular}{|c|c|c|c|}
\hline 실제길이 & 실험 1 [\%] & 실험 2[\%] & 실험 3[\%] \\
\hline $1.25 \mathrm{~cm}$ & - & 6.532 & - \\
\hline $1.5 \mathrm{~cm}$ & 7.083 & 7.104 & 6.533 \\
\hline $2.0 \mathrm{~cm}$ & 5.580 & 7.944 & 6.989 \\
\hline $3.0 \mathrm{~cm}$ & 11.075 & 10.273 & 11.192 \\
\hline $5.0 \mathrm{~cm}$ & 10.968 & 10.998 & 10.057 \\
\hline
\end{tabular}

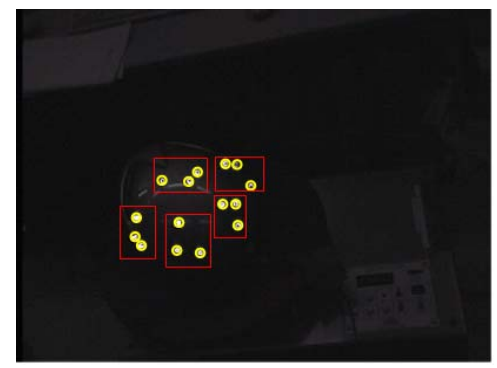

그림 7. 헬멧에 부착된 패턴

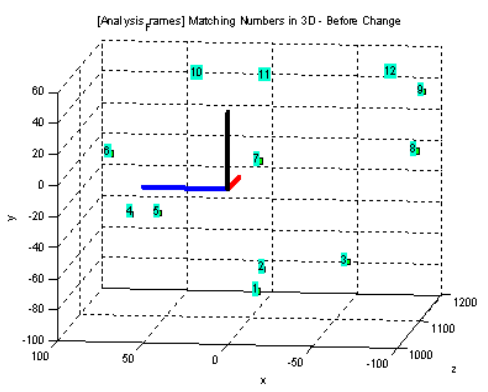

그림 8. 매칭 순서가 부여된 특징점

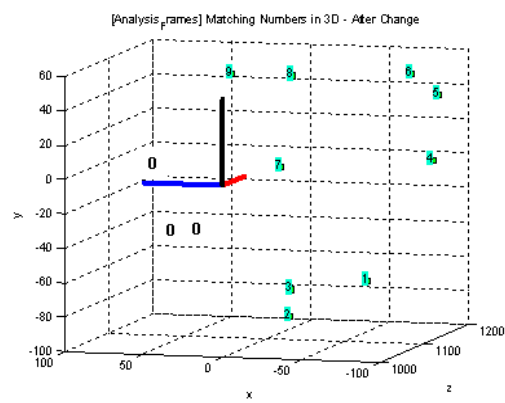

그림 9. 획득된 특징점 고유 번호

여기서 0 번으로 표시된 점은 현재 획득된 특징점 들 중 완전한 하나의 패턴을 이루지 못하는 점들 을 나타낸다. 그림 8과 비교해 보았을 때, 새로운 번호가 부여된 것을 확인할 수 있다.

3) 자세 획득

헬멧의 회전 실험을 통해 패턴 매칭 알고리즘 의 성능을 분석한다. 1축 레이트 테이블에 헬멧 을 올려놓고 $\mathrm{z}$ 축을 중심으로 10 초동안 $8 \mathrm{deg} / \mathrm{sec}$ 의 속력으로 회전 시켰다. 그림 10 은 $\mathrm{z}$ 축을 중심 으로 80 도 회전시킨 실험의 요(yaw) 결과이다.

영상 분석 결과 80 도만큼 회전 시켰을 때, 81.65 도만큼 회전이 되었음을 알 수 있다. 오차는 1.65 도이며 전체적으로 실제 헬멧의 움직임과 일치한 다.

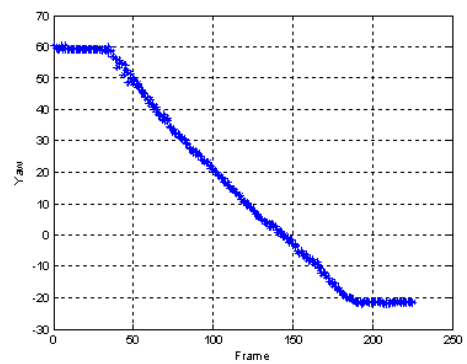

그림 10. $\mathrm{z}$ 축 80 도 회전 실험의 요 결과 


\section{III. 결 론}

기존의 헤드 트랙커는 초기자세를 획득할 때 오랜 시간 동안 헬멧이 고정된 상태에서 특징점 이 하나씩 점등해야 하는 제약이 존재하였다. 본 논문에서는 이를 개선하기 위해 패턴을 이용한 방식을 제안하였다.

패턴은 특징점간 거리를 통하여 획득되기 때 문에 특징점간 거리 실험을 선행하였다. 이 실험 을 통해 획득된 최소 구분 거리와 최대 오차율을 이용하여 패턴을 형성하고 배치하였다. 그리고 최소자승법을 통해 맵 데이터와 비교하여 머리의 위치 및 자세를 획득하는 실험을 하였다.

실험 결과 그림 10 과 같이 전체적으로 헬멧의 위 치 및 자세를 잘 추정하고 있으며 오차는 1 도내외 의 값을 보이고 있다. 오차는 스테레오 카메라의 해 상도 한계와 회전에 따른 특징점 방사 형태의 변화 로 정확한 특징점의 중심을 찾지 못했기 때문이다.

본 논문의 목적은 빠른 시간 안에 정확한 초기 자세를 획득하기 위한 것이므로 생각할 때 제안하 는 알고리즘은 성공적으로 적용됨을 알 수 있다. 기존 시스템은 헬멧이 고정된 상태로 장시간 특징 점의 점등을 기다려야 했지만, 제안하는 알고리즘 을 이용하면 시스템의 시작과 함께 초기자세를 바 로 획득할 수 있다. 그러나 오차가 존재하기 때문 에 1초(15프레임)정도 시스템 구동 시간을 두어 머리 움직임의 추세를 파악한 후, 초기자세를 획 득하는 것이 적합한 방법이라 생각한다. 그러므로 제안하는 알고리즘은 패턴 매칭을 이용하여 초기 자세 획득 방식을 개선시켰다고 판단되며, 향후 관성 방식과 결합하여 패턴 매칭을 적용한 하이브 리드 헤드 트랙커 시스템 연구에 응용될 수 있다.

\section{후 기}

본 연구는 방위사업청과 국방과학연구소의 지 원으로 수행되었으며, 이에 대해 깊이 감사를 드 립니다(계약번호 UD070041AD).

\section{참고문헌}

1) Guilio Douhet, The command of the air, Coward-McCann, Inc., New York, 1984.

2) Young Jun Lee, Chan Gook Park ,and Seok Ki Hong, "Helmet Tracker System Using Stereo Cameras", SICE-ICCAS, Bexco, Busan, 2006.W.

3) E.Foxline, Y.Altshuler, L.Naimark and M.Harrington, InterSense, Inc., "Flight Tracker : A Novel Optical/Inertial Tracker for Cockpit Enhanced Vision", IEEE/ACM International Symposiumon Mixedand Augmented Reality (ISMAR2004), Arlington, VA, USA, November 2 5, 2004.

4) Young il Kim, Young Jun Lee, Jun Kyu Lim, Chan Gook Park, "Hybrid Head Tracker System to Compose Optical/ Inertial Head Tracker System", ICSIIT 2007, Bali, Indonesia, July 26 27, 2007.

5) E. Foxlin, Motion Tracking Requirements and Technologies, ed.Stanney, Lawrence Erlbaum Associates, 2002.

6) SPICA Technology Co., Helmet Tracker, 2005.

7) Linda Tessens, Roland Kehl, Aleksandra Pizurica, Luc Van Gool and Wilfried Philips, "A Real-time Optical head Tracker Based On 3D Prediction and Correction", SPS-DARTS, 2006, pp. 39 42.

8) 홍석기, “적외선 카메라와 관성 센서를 이 용한 하이브리드 헤드 트랙커", 서울대학교 대학 원 기계항공공학부, 2006.

9) 이영준, “확장 칼만필터 기반의 입자필터를 사용한 광학방식 헤드 트랙커 알고리즘", 서울대 학교 대학원 기계항공공학부, 2008. 